\title{
Functional characterization of the FimH adhesin from Salmonella enterica serovar Enteritidis
}

\begin{abstract}
Correspondence
Maciej Ugorski

ugorski@ozi.ar.wroc.pl
\end{abstract}

Received 13 October 2005

Revised 11 January 2006

Accepted 24 January 2006

\author{
Dagmara Kisiela, ${ }^{1}$ Anna Laskowska, ${ }^{3}$ Anna Sapeta, ${ }^{1}$ Maciej Kuczkowski, ${ }^{2}$ \\ Alina Wieliczko ${ }^{2}$ and Maciej Ugorski ${ }^{1,3}$
}

1,2Departments of Biochemistry, Pharmacology and Toxicology ${ }^{1}$ and of Epizootiology and Veterinary Administration with Clinic ${ }^{2}$, Faculty of Veterinary Medicine, Agricultural University of Wroclaw, Cypriana Norwida 31, 50-375 Wroclaw, Poland

${ }^{3}$ Department of Immunochemistry, Ludwik Hirszfeld Institute of Immunology and Experimental Therapy, Polish Academy of Sciences, Rudolfa Weigla 12, 53-114 Wroclaw, Poland
Salmonella enterica serovar Enteritidis has emerged during the last 20 years as the major causative agent of food-borne gastroenteritis in humans and as the major infectious agent on poultry farms, replacing Salmonella enterica serovar Typhimurium as the dominant pathogenic serovar.

Because adhesion to gut tissues and colonization of the alimentary tract, mediated in large part by the FimH adhesins located on type 1 fimbriae, is an important stage in the pathogenesis of both serovars, the binding properties of the $\mathrm{FimH}$ adhesins from these two enteropathogens were compared. Salmonella Enteritidis FimH protein and the Salmonella Typhimurium low-adhesive variant of this adhesin were expressed in Escherichia coli and the recombinant proteins were analysed for their ability to bind glycoproteins carrying different oligomannosidic structures and different types of eukaryotic cells. In static binding assays (ELISA and Western blotting) both FimH proteins bound equally well to all three tested glycoproteins (RNase $B$, horseradish peroxidase and mannan-BSA). In addition, no differences were found in the binding specificity of the FimH proteins and intact cells of Salmonella Enteritidis and Salmonella Typhimurium to human colon carcinoma or bladder cancer cells. The presence of the same amino acid residues at positions 61 (glycine) and 118 (phenylalanine) and the similar binding properties of these two adhesins suggest that the newly described FimH protein of Salmonella Enteritidis represents the low-adhesive variant found in Salmonella Typhimurium. To study the binding specificity of Salmonella Enteritidis FimH protein further, direct kinetic analysis using surface plasmon resonance was performed. With this method it was found that Salmonella Enteritidis FimH adhesin bound with the highest $K_{d}$ value to high-mannose type $N$-glycans carried by RNase B; about 100 times lower $K_{d}$ values were obtained in the interactions with mannan-BSA and horseradish peroxidase.

\section{INTRODUCTION}

Salmonella enterica serovar Enteritidis is presently the major causative agent of food-borne gastroenteritis in humans worldwide and an important source of bacterial infections on poultry farms, resulting in public health problems and high economic costs. Infection by Salmonella Enteritidis is initiated by the attachment and colonization of the gut mucosa, which seems to be an essential stage in the pathogenesis of salmonellosis. Increasing evidence suggests that bacterial fimbriae play an important role in these processes (De Buck et al., 2003; Dibb-Fuller et al., 1999; Dibb-Fuller \&

Abbreviations: c-ELISA, cellular-ELISA; GuHCl, guanidine hydrochloride; HRP, horseradish peroxidase; mannan-BSA, mannosylated bovine serum albumin; Ni-NTA, nickel-nitrilotriacetic acid; SPR, surface plasmon resonance.
Woodward, 2000; Ewen et al., 1997; Naughton et al., 2001), although their exact role in the pathogenesis of Salmonella is still controversial (Rajashekara et al., 2000; Allen-Vercoe \& Woodward, 1999; Allen-Vercoe et al., 1999).

Fimbriae are proteinaceous filamentous structures present on the surface of many members of the Enterobacteriaceae, including the genus Salmonella (Duguid et al., 1966; Thorns, 1995). The Salmonella enterica serovar Enteritidis genome contains many putative fimbrial operons: agf, $b c f$, fim, lpf, pef, saf, sef, stb, stc, std, ste, stf, sth, sti (Edwards et al., 2002; Porwolik \& McClelland, 2003); however, expression of fimbrial proteins encoded by these operons has only been demonstrated for a few of them. It has been shown that Salmonella Enteritidis elaborates fimbriae designated SEF21 (encoded by the fim operon) (Müller et al., 1991), SEF17 (encoded by the agf operon) (Collinson et al., 1996), SEF14 
(encoded by the sefoperon) (Clouthier et al., 1993), and LPF fimbriae (encoded by the lpf operon) (Barrow, 1998), and the expression of type IV fimbriae called bundle-forming pili has also been suggested (Sohel et al., 1993). In addition, Salmonella Enteritidis produces PEF fimbriae encoded by the plasmid-localized pef operon (Woodward et al., 1996).

SEF21 are type 1 fimbriae, which are the most common and one of the best-characterized enterobacterial adhesive structures (Abraham, 1994; Clegg \& Gerlach, 1987). Type 1 fimbriae are composed primarily of protein subunits (fimbrins) called FimA. However, their binding properties depend on another auxiliary protein called FimH (Krogfelt et al., 1990). This lectin-like adhesin, located on the tip of the fimbrial shaft, is directly responsible for bacteria binding to oligomannosidic structures carried by many eukaryotic membrane-bound and secreted glycoproteins.

Based on the early studies, it was proposed that FimH proteins of Enterobacteriaceae are closely related structurally and immunologically (Abraham et al., 1988) and that all strains within a genus exhibit the same sugar specificity (Old, 1972). However, it has become increasingly clear that there is significant heterogeneity among type 1 fimbriae from different genera and even within the same species in their binding affinities for certain mannosylated compounds. It has been found that allelic variants of the FimH adhesin from Escherichia coli strains, differing only in one amino acid residue, have different receptor specificities and, in addition to high-mannose-type oligosaccharides, can bind single monomannnose residues (Sokurenko et al., 1994, 1995). Recently, similar observations were made for Salmonella Typhimurium. Two strains of this Salmonella serovar, expressing allelic variants of FimH protein differing by two amino acid residues, adhering weakly and strongly to human HEp-2 cells, were described by Boddicker et al. (2002).

Studies on Salmonella Typhimurium revealed that FimH adhesin is responsible for bacteria binding to HeLa, HEp-2 (Boddicker et al., 2002; Hancox et al., 1998) and mouse intestinal epithelial cells (Thankavel et al., 1999), and the functional characteristics as well as binding specificity of Salmonella Typhimurium FimH adhesin were investigated. In contrast, relatively little is known about the binding specificity of FimH adhesin from Salmonella Enteritidis, although this serovar is presently the major causative agent of food-borne gastroenteritis in humans. Therefore, as a first step, the fimH gene of Salmonella Enteritidis was cloned and sequenced (Kisiela et al., 2005a). A comparison of the predicted amino acid sequence of FimH adhesin from Salmonella Enteritidis with active FimH adhesin from Salmonella Typhimurium and two inactive FimH adhesins from biovars Gallinarum and Pullorum revealed that both inactive proteins were characterized by the presence of isoleucine at position 78 instead of the threonine found in the active FimH adhesin of Salmonella Typhimurium (Kisiela et al., 2005b). As we have shown previously, the replacement of this isoleucine with threonine (I78T) in the FimH molecules by site-directed mutagenesis caused the mutated FimH proteins of biovar Gallinarum and biovar Pullorum to bind well to both glycoproteins carrying high-mannose oligosaccharides and colon carcinoma cells, proving that the loss of sugar-binding properties by biovar Gallinarum and biovar Pullorum FimH adhesins is most probably the result of a single T78I mutation. Based on these results, the functional characteristics of FimH adhesin from Salmonella Enteritidis and the importance of Thr78 in the binding activity of this protein were investigated further in this study.

\section{METHODS}

Bacterial strains and plasmids. The Salmonella Enteritidis strain (isolate no. 327) collected from broiler chicken, and the isolate of the serovar Typhimurium collected from laying hens have been described elsewhere (Kisiela et al., 2005a, b). E. coli strain DH5 $\alpha$, used as the host for the expression of the recombinant proteins, was routinely grown at $37{ }^{\circ} \mathrm{C}$ in Super Broth medium (SB, 3.0\% tryptone, $2.0 \%$ yeast extract, $1 \cdot 0 \%$ MOPS; Roth) containing $100 \mu \mathrm{g}$ ampicillin $\mathrm{ml}^{-1}$ (Polfa Tarchomin). Plasmid E.fimH/pTrcHis2b, containing fimH of Salmonella Enteritidis, was constructed analogously to plasmid T.fimH/pTrcHis2b with cloned Salmonella Typhimurium fimH, as described previously (Kisiela et al., 2005b).

Cells and cell culture. The human colon carcinoma HT-29 and bladder carcinoma $\mathrm{Hu} 1703 \mathrm{He}$ cell lines were obtained from the Cell Line Collection of the Institute of Immunology and Experimental Therapy, Wroclaw, Poland. HT-29 cells were cultured in $\alpha$-minimal essential medium $(\alpha$-MEM) and Hu 1703He cells in Fib41B medium supplemented with non-essential amino acids (Christensen et al., 1984). Each medium was supplemented with $10 \%$ fetal calf serum (Gibco-BRL), $2 \mathrm{mM}$ glutamine (Sigma) and antibiotics.

Chicken mucosal epithelial cells were isolated according to the procedure described by Kimmich (1970). Six-week-old chickens were killed by decapitation and the entire small intestine was removed from the abdominal cavity, isolated and washed several times with cold PBS. It was than cut into small pieces that were placed in $20 \mathrm{ml}$ incubation medium [20 mM Tris/ $\mathrm{HCl}, \mathrm{pH} 7 \cdot 4$, containing $120 \mathrm{mM} \mathrm{NaCl}, 3 \mathrm{mM}$ $\mathrm{K}_{2} \mathrm{HPO}_{4}, 1 \mathrm{mM} \mathrm{MgCl}{ }_{2}, 1 \mathrm{mM} \mathrm{CaCl}$ and $1 \mathrm{mg}$ hyaluronidase $\mathrm{ml}^{-1}$ (Sigma)] and incubated at $37^{\circ} \mathrm{C}$ for 30 min with moderate shaking. Epithelial cells were then collected by agitation of the intestinal pieces with the tip of a pipette. The cell suspension was filtered through a nylon filter and centrifuged for $1 \mathrm{~min}$ at $100 \mathrm{~g}$ to obtain a pellet of intact cells. The cells were washed several times with incubation media without hyaluronidase.

Expression, isolation and purification of recombinant FimH protein. E. coli $\mathrm{DH} 5 \alpha$ cells transformed with expression vectors E.fimH/pTrcHis $2 b$ or T.fimH/pTrcHis2b were grown at $37^{\circ} \mathrm{C}$, with constant shaking, in $150 \mathrm{ml} \mathrm{SB}$ medium containing $100 \mu \mathrm{g}$ ampicillin $\mathrm{ml}^{-1}$ and $20 \mathrm{mM} \mathrm{MgCl}$. When the $\mathrm{OD}_{600}$ of the growing culture reached $0 \cdot 2$, IPTG (Fermentas) was added to a final concentration of $1 \mathrm{mM}$. The temperature was lowered to $28^{\circ} \mathrm{C}$ and incubation was continued for another $12-16 \mathrm{~h}$. To isolate FimH protein, bacteria were centrifuged, suspended in $50 \mathrm{mM}$ sodium phosphate/300 mM $\mathrm{NaCl} \mathrm{pH} 8 \cdot 0$, and broken by sonication. Recombinant fimbrial proteins were purified on nickel-nitrilotriacetic acid (Ni-NTA) resin using a $6 \times$ His affinity tag located at the carboxy terminus of the proteins, according to the conditions recommended by the manufacturer (Qiagen). The purified fractions were collected, dialysed against distilled water and lyophilized. The proteins were solubilized in PBS or TBS and quantified by the bicinchoninic acid protein assay kit (Sigma). 
Biotinylation of FimH proteins. Biotinylation of proteins was performed according to the method described by Duk et al. (1994). Two hundred micrograms of protein in $250 \mu \mathrm{l}$ PBS was mixed with $400 \mu \mathrm{l}$ of a $0.025 \%$ solution of biotinamidocaproate- $N$-hydroxysuccinimide ester (Sigma) in PBS and incubated $30 \mathrm{~min}$ at room temperature. The sample was dialysed for several hours against water and then against TBS.

Synthesis of mannosylated BSA (mannan-BSA). Mannan-BSA was synthesized according to the method of Boratynski \& Roy (1998). Briefly, BSA solution $\left(10 \mathrm{mg} \mathrm{ml}^{-1}\right.$, Sigma) was mixed with an equal volume of mannan $\left(10 \mathrm{mg} \mathrm{ml}^{-1}\right.$, Sigma). The resulting solution was supplemented with dimethylformamide $\left(15 \mu \mathrm{ml}^{-1}\right)$. The samples were frozen in an acetone-dry ice bath and lyophilized. Lyophilizates were then heated at $118^{\circ} \mathrm{C}$ for $20 \mathrm{~min}$ and dissolved in TBS.

SDS-PAGE and Western blotting. Cell lysates were obtained by solubilizing cells in a lysis buffer: $50 \mathrm{mM}$ Tris/ $\mathrm{HCl} \mathrm{pH} 8 \cdot 0,150 \mathrm{mM}$ $\mathrm{NaCl}, 1 \mathrm{mM}$ EDTA containing $0 \cdot 5 \% \mathrm{NP} 40,1 \mathrm{mM}$ phenylmethylsulphonyl fluoride, aprotinin $\left(2 \mu \mathrm{g} \mathrm{ml}^{-1}\right)$ and leupeptin $\left(2 \mu \mathrm{g} \mathrm{ml}^{-1}\right)$. The proteins were quantified by the bicinchoninic acid protein assay kit (Sigma). Cell lysate samples or high-mannose glycoproteins [RNase B, horseradish peroxide (HRP) and mannan-BSA] were subjected to SDS-PAGE in $7 \cdot 5 \%$ or $10 \%$ gel respectively (Laemmli, 1970). The proteins were then transferred to nitrocellulose (Schleicher \& Schull). Blotted proteins were incubated with biotinylated, recombinant FimH $\left(20 \mu \mathrm{g} \mathrm{ml}^{-1}\right)$ and immunologically detected with alkaline-phosphatase-conjugated streptavidin (Sigma). The specificity of FimH binding to glycoproteins and cell lysates was examined by preincubation of the adhesins with $0.2 \mathrm{M} \alpha$-D-mannose in TBS for $1 \mathrm{~h}$ at room temperature. Purified FimH proteins, separated on a $10 \%$ gel by SDS-PAGE and blotted onto nitrocellulose were detected immunologically with primary anti-myc mAb 9E10 (ATCC, no. CRL-1729) and alkaline phosphatase-conjugated goat anti-mouse immunoglobulins (Dako).

ELISA assay. Microtitre plates (96-well) (Nunc, Maxisorp) were coated with $100 \mu \mathrm{l}$ RNase B (Sigma), HRP (Sigma) or mannan-BSA $(2 \mu \mathrm{g}$ per well) in $0.05 \mathrm{M}$ carbonate buffer, $\mathrm{pH} 9 \cdot 6$, overnight at $4{ }^{\circ} \mathrm{C}$. The wells were washed and blocked with $1 \%$ casein (Sigma) in TBS for $1 \mathrm{~h}$. Immobilized mannosylated compounds were incubated with twofold serial dilutions of purified biotinylated-recombinant FimH, starting from $100 \mu \mathrm{g} \mathrm{ml}^{-1}$, in TBS buffer for $1 \mathrm{~h}$ at room temperature. The plates were washed again with TBS and incubated with alkaline-phosphatase-conjugated streptavidin (Sigma), diluted $1: 2000$, for another hour at room temperature. After washing, the reaction was developed with $p$-nitrophenyl phosphate (Fermentas) in $0.05 \mathrm{M}$ carbonate buffer, $\mathrm{pH} 9 \cdot 6$. The absorbance was read at $405 \mathrm{~nm}$. For cellular-ELISA assay (c-ELISA), cell monolayers growing in 96-well plates (Sarstedt) were washed with PBS and incubated with $1 \%$ casein (Sigma) in PBS for $1 \mathrm{~h}$ at room temperature. All other steps were performed as described for the ELISA assay, except that PBS was used instead of TBS buffer.

Real-time interaction analysis by surface plasmon resonance (SPR). The binding of FimH proteins to immobilized glycoproteins was analysed using a BIAcore 1000. CM5 (BIAcore) sensor chips with carboxymethylated dextran matrix were used throughout these studies. Immobilization of glycoproteins to a sensor chip was carried out using the Amine Coupling kit following the instructions from the manufacturer. Briefly, after activation of the sensor surface with the mixture EDC/NHS, the solutions of RNase $\mathrm{B}\left(0 \cdot 15 \mathrm{mg} \mathrm{ml}^{-1}\right.$ in $5 \mathrm{mM}$ maleate buffer, pH 5.2), HRP $\left(0 \cdot 15 \mathrm{mg} \mathrm{ml}^{-1}\right.$ in $5 \mathrm{mM}$ maleate buffer, $\mathrm{pH} 6 \cdot 0)$, or mannan-BSA $\left(0 \cdot 15 \mathrm{mg} \mathrm{ml}^{-1}\right.$ in $10 \mathrm{mM}$ acetate buffer, $\mathrm{pH} 4 \cdot 2$ ) were injected over the sensor surface for 2-5 min to allow optimal immobilization, followed by $50 \mu \mathrm{l} 1 \mathrm{M}$ ethanolamine to deactivate the unreacted NHS esters. The amounts of bound proteins corresponded to approximately 1300 response units (RU) for RNase B and HRP, and 3400 RU for mannan-BSA. The chip was equilibrated with the running buffer (50 mM TBS, $\mathrm{pH} 7 \cdot 4, T=25^{\circ} \mathrm{C}$ ) until a stable baseline was obtained. All binding experiments were carried out at $25^{\circ} \mathrm{C}$ with a constant flow rate of $2 \mu \mathrm{min}^{-1}$. The channel with no protein bound was used as a control of non-specific binding. To determine the affinity of FimH adhesins for glycoproteins, $20 \mu \mathrm{l}$ of the FimH solutions $[0.4 \mathrm{mg}$ $\mathrm{ml}^{-1}$ in running buffer with $0.2 \mathrm{M}$ guanidine hydrochloride $(\mathrm{GuHCl})]$ were passed over the ligand-immobilized chip (association phase) followed by $10 \mathrm{~min}$ dissociation with the running buffer. The chip surface was regenerated by a $2 \mathrm{~min}$ pulse of $1 \mathrm{M} \mathrm{NaCl}, 50 \mathrm{mM}$ $\mathrm{NaOH}$. BIAevaluation 3.1 software was used to perform the quantification of the association and dissociation rate constants.

Site-directed mutagenesis. The mutagenesis of Salmonella Enteritidis and Salmonella Typhimurium fim $H$ genes was performed using a PCR-based method. The mutation of interest (T78I) was generated by two separate PCR reactions using two pairs of primers. PCR I was carried out with the original $5^{\prime}$-fim primer common to both fimH genes ( $5^{\prime}$-CGCGGATCCAATGAAAATATACTCAGC-3'), a $3^{\prime}$-primer containing the desired T78I mutation (5'-GCTTCGGTAGATATAATTTACCGTTGTCC-3' for Salmonella Enteritidis and 5'-CTTCGGTAGATATAATTCACCGTTGTCC-3' for Salmonella Typhimurium), and the plasmid (E.fimH/pTrcHis2b or T.fimH/ pTrcHis2b) as a template. PCR II was performed with the original $3^{\prime}$-fim primer common to both fimH genes (5'-GCGTCTAGAGCATCATAATCGACTCG-3'), a $5^{\prime}$-primer carrying the mutation (5'-GGACAACGGTAAATTATATCTACCGAAGC-3' for Salmonella Enteritidis and 5'-GGACAACGGTGAATTATATCTACCGAAG-3' for Salmonella Typhimurium) and the same template as before. The resulting DNA fragments were used as a template for the third PCR with the original primers for the fim $H$ genes. The reaction mixtures $(50 \mu \mathrm{l})$ contained $100 \mathrm{ng}$ plasmid, 20 pmol each primer, $10 \mathrm{nM}$ each dNTP (Qiagen) and 1 U Taq DNA polymerase (Qiagen). In each case, amplification was performed as follows: $1 \mathrm{~min}$ at $94^{\circ} \mathrm{C}$, $1 \mathrm{~min}$ at $54{ }^{\circ} \mathrm{C}$ and $1 \mathrm{~min}$ at $72^{\circ} \mathrm{C}(25$ cycles $)$. The mutations introduced into the Salmonella Enteritidis and Salmonella Typhimurium fimH genes were confirmed by DNA sequencing. Mutated fim $H$ genes were cloned into pTrcHis2b plasmid and expressed in E. coli $\mathrm{DH} 5 \alpha$ as described for wild-type FimH adhesins. The expression vectors containing the mutated genes were designated mutE.fimH/ pTrcHis2b for Salmonella Enteritidis and mutT.fimH/pTrcHis2b for Salmonella Typhimurium.

Adherence assay. For the adherence assay, Salmonella Enteritidis and Salmonella Typhimurium were passaged five times in static LB broth at $37^{\circ} \mathrm{C}$. Bacteria at a concentration of $1 \times 10^{8}$ c.f.u. $\mathrm{ml}^{-1}$, suspended in PBS, were added to the confluent 3-day HT-29 or Hu $1703 \mathrm{He}$ cell monolayers, growing in a 24 -well plate (Sarnstedt) and incubated at room temperature for $2 \mathrm{~h}$ on a tabletop rotator. After incubation, non-adherent bacteria were removed from the monolayers by washing five times with PBS. Cell-associated bacteria were liberated by treatment with $0 \cdot 2 \%$ Triton X-100 (Sigma) for $20 \mathrm{~min}$ (500 $\mu \mathrm{l}$ per well). Bacterial suspensions were serially diluted with PBS and plated on SB-agar, incubated overnight at $37^{\circ} \mathrm{C}$, and the colonies were counted to calculate the c.f.u. The adherence assay was also performed in the presence of $0 \cdot 2 \mathrm{M}$ D-mannose. Each assay was conducted in triplicate and was independently repeated at least three times.

Flow cytometry. For flow cytometry, Salmonella strains were grown as described for the adherence assay. Flow cytometry was performed according to the method described by Humphries et al. (2003), with minor modifications. In brief, approximately $5 \times 10^{8}$ cells were harvested by centrifugation and washed twice in PBS, resuspended in $0.5 \mathrm{ml} \mathrm{PBS}$ and incubated with an equal volume of $4 \%$ paraformaldehyde (Sigma) at room temperature for $20 \mathrm{~min}$. Then the cells were washed once with $1 \mathrm{ml}$ PBS. To block non-specific binding, 
cells were harvested and resuspended in $0.5 \mathrm{ml} 1 \%$ casein and incubated at room temperature for $30 \mathrm{~min}$. For the detection of FimH proteins, bacteria, after washing with $1 \mathrm{ml}$ PBS, were incubated with preadsorbed rabbit anti-FimH serum (Kisiela et al., 2005b) diluted $1: 100$ in PBS in a final volume $0.5 \mathrm{ml}$. The bacteria were incubated at room temperature for $1 \mathrm{~h}$ and then washed twice with PBS. The bacterial cells were resuspended in $0.5 \mathrm{ml} 0.04 \mathrm{mM}$ propidium iodide and FITC-conjugated goat anti-rabbit IgG (Sigma) was added at a dilution of $1: 250$. The bacteria were incubated at room temperature for $1 \mathrm{~h}$ in the dark, washed three times with PBS and resuspended in PBS to a final concentration of approximately $5 \times 10^{6}$ cells $\mathrm{ml}^{-1}$. Flow cytometry analysis was performed using FACScan (Becton Dickinson). For each sample, the fluorescence of 10000 events was measured.

\section{RESULTS}

\section{Expression of recombinant FimH proteins in E. coli}

The FimH proteins of Salmonella Enteritidis and Salmonella Typhimurium were overexpressed in E. coli $\mathrm{DH} 5 \alpha$ and purified by chromatography on Ni-NTA affinity matrix. SDS-PAGE of the purified FimH proteins revealed the presence of a major band with an apparent molecular mass of about $36 \mathrm{kDa}$ and several additional minor bands of higher molecular masses (Fig. 1a, b, lanes 1), representing protein aggregates. The small difference in molecular mass compared with the previously published $35 \mathrm{kDa}$ (Thankavel et al., 1999) is due to the additional sequences (c-myc epitope and $6 \times$ His-tag) present in the recombinant protein. The identity of FimH proteins was confirmed by Western blotting with $\mathrm{mAb} 9 \mathrm{E} 10$ directed against the c-myc epitope present in the recombinant proteins (Fig. 1a, b, lanes 2). In addition, in the preparations of FimH from both Salmonella serovars two faster-migrating bands with apparent molecular (a)

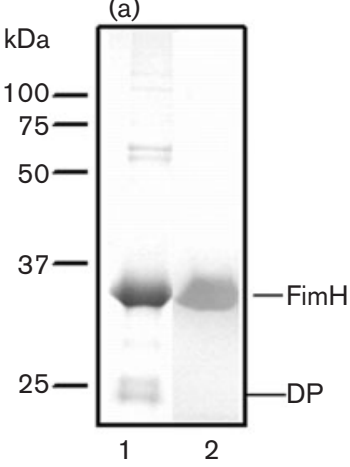

(b)

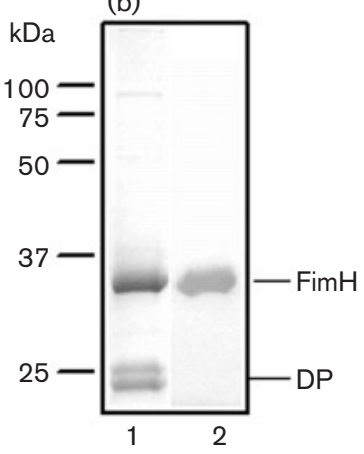

Fig. 1. Coomassie-blue-stained SDS-PAGE (lanes 1) and immunostaining with anti-myc mAb 9E10 (lanes 2) of recombinant FimH adhesins from (a) Salmonella Enteritidis and (b) Salmonella Typhimurium. FimH proteins $(10 \mu \mathrm{g})$, purified on Ni-NTA resin, were subjected to SDS-PAGE under reducing conditions in $10 \%$ gel. The migration positions of protein standards (in $\mathrm{kDa}$ ) are indicated on the left. $\mathrm{DP}$, degradation products. masses in the range of $25 \mathrm{kDa}$ were also present (Fig. 1a, b, lanes 1). These protein bands were not detectable with $\mathrm{mAb}$ 9E10, although they were stained with rabbit antibodies directed against FimH proteins (data not shown). They most likely represent the product of proteolytic degradation of FimH.

\section{Construction and expression of fimH gene mutants}

T78I mutants of the Salmonella Enteritidis and Salmonella Typhimurium fim $\mathrm{H}$ genes were constructed as described in Methods and cloned into plasmid pTrcHis2b (mutE.fimH/ $\mathrm{p} \operatorname{TrcHis} 2 \mathrm{~b}$ and mutT.fimH/pTrcHis2b). The entire insert, amplified by PCR, was sequenced to rule out the presence of potential mutations introduced by PCR.

E. coli $\mathrm{DH} 5 \alpha$ cells were transformed with plasmids containing mutated fim $\mathrm{H}$ genes (mutE.fimH/pTrcHis $2 \mathrm{~b}$ and mutT. fimH/pTrcHis2b), and recombinant FimH adhesins after purification were analysed by Western blotting. They gave the same pattern of binding with anti-FimH antibodies as did wild-type FimH proteins (data not shown).

\section{Binding specificity of Salmonella Enteritidis and Salmonella Typhimurium recombinant FimH adhesins and their mutants}

The functional activity and specificity of recombinant FimH proteins were examined by their ability to bind glycoproteins carrying mannose-rich carbohydrate chains (RNase B and HRP) and synthetic glycoconjugate mannan-BSA. Both biotinylated FimH adhesins bound to all the analysed glycoproteins carrying different oligomannosidic structures as shown by Western blotting (Fig. 2a, c). The binding was

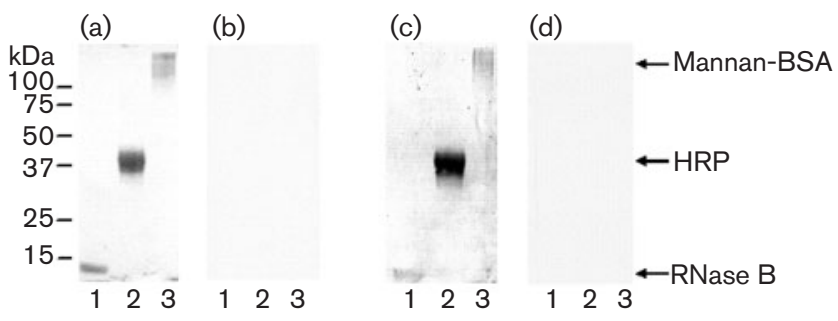

Fig. 2. Western blot analysis of FimH binding to glycoproteins carrying high-mannose-type oligosaccharide chains. Binding of the wild-type (a) and mutant (b) FimH adhesins of Salmonella Enteritidis and wild-type (c) and mutant (d) FimH adhesins of Salmonella Typhimurium to RNase B (lane 1), HRP (lane 2) and mannan-BSA (lane 3). The mutants, constructed by sitedirected mutagenesis, are identical to wild-type adhesins except at the position corresponding to the amino acid at position 78 , where threonine was replaced by isoleucine (T78I). Individual glycoproteins $(10 \mu \mathrm{g})$ were subjected to SDS-PAGE under reducing conditions in $10 \%$ gel and electrophoretically transferred onto nitrocellulose. The migration positions of protein standards (in $\mathrm{kDa}$ ) are indicated on the left. 
completely inhibited by preincubating FimH with $0 \cdot 2 \mathrm{M} \mathrm{D}$ mannose (data not shown). In contrast, both mutated FimH adhesins completely lost their binding properties to RNase B and HRP as well as to mannan-BSA (Fig. 2b, d).

To compare the binding properties of FimH proteins from Salmonella Enteritidis and Salmonella Typhimurium, ELISA assay was performed. With this assay we were able to show that FimH proteins of both serovars bound equally well to all the tested glycoproteins (Fig. 3a-c). Further characterization of bacterial FimH lectins was done by the c-ELISA assay, used to measure their interactions with the human cell lines (Fig. 4a, b). Similar binding of Salmonella Enteritidis and Salmonella Typhimurium FimH adhesin was observed for the human colon carcinoma cell line HT-29 and human bladder cancer cell line $\mathrm{Hu} 1703 \mathrm{He}$.

To determine the nature of the receptors for these bacterial lectins present in the analysed cells, we performed Western blotting with the above human cell lysates and biotinylated
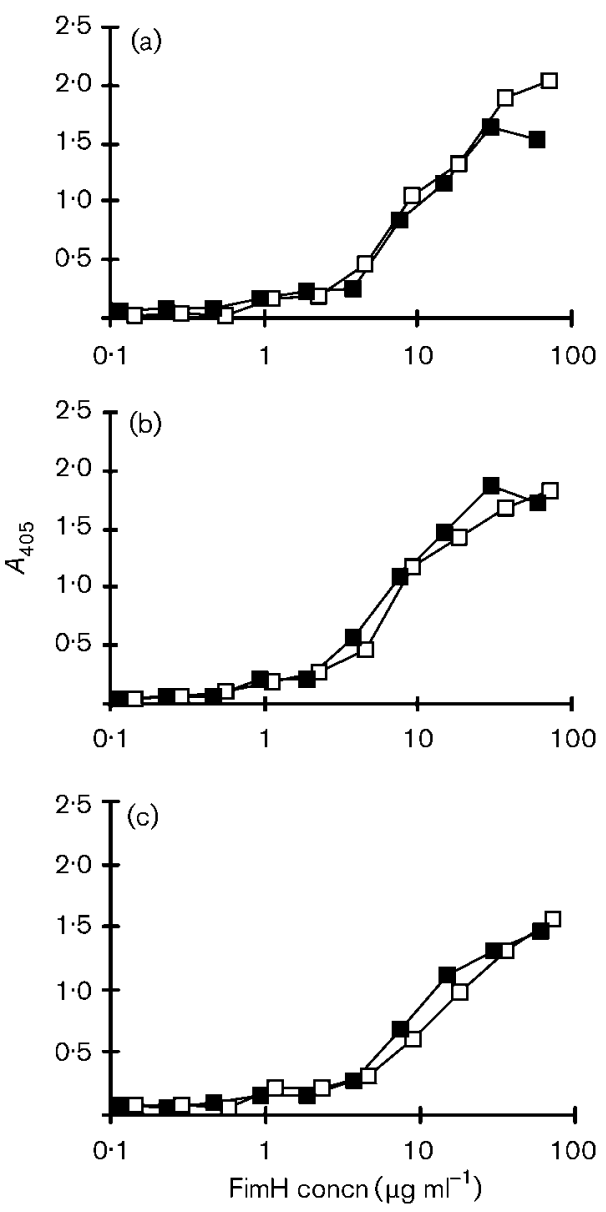

Fig. 3. Binding of serially diluted FimH adhesins to ELISA plates coated with (a) RNase B, (b) HRP and (c) mannan-BSA. The plates were coated with glycoprotein solutions at $20 \mu \mathrm{g} \mathrm{ml}^{-1}$. $\square$, FimH of Salmonella Enteritidis; $\mathbf{0}$, FimH of Salmonella Typhimurium.

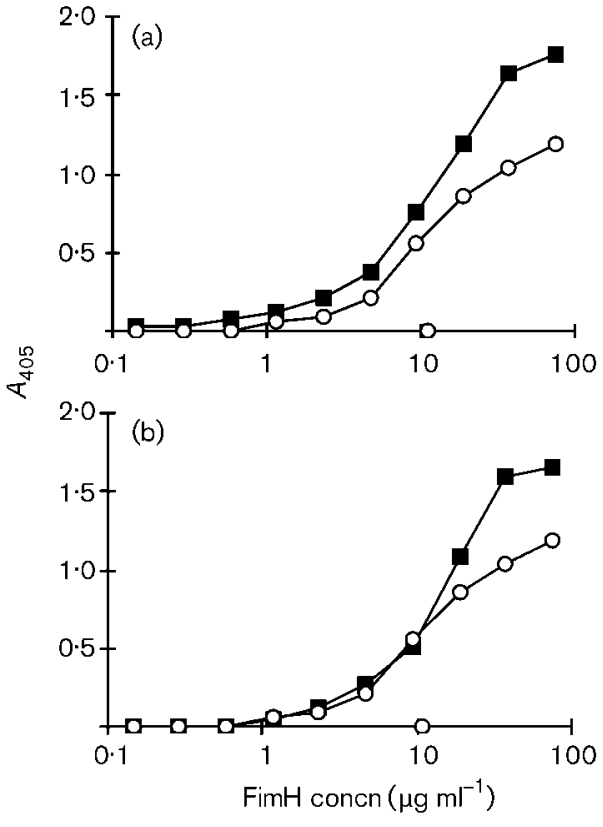

Fig. 4. Binding of serially diluted FimH adhesins of (a) Salmonella Enteritidis and (b) Salmonella Typhimurium to cell monolayers growing in 96-well plates. 口, HT-29 (human colon cancer cell line); $\bigcirc, \mathrm{Hu} 1703 \mathrm{He}$ (human bladder carcinoma cell line).

FimH proteins. In addition, freshly isolated chicken enterocytes were analysed. As shown in Fig. 5 (a, b), FimH proteins bound in each case to numerous protein bands, but the (a)

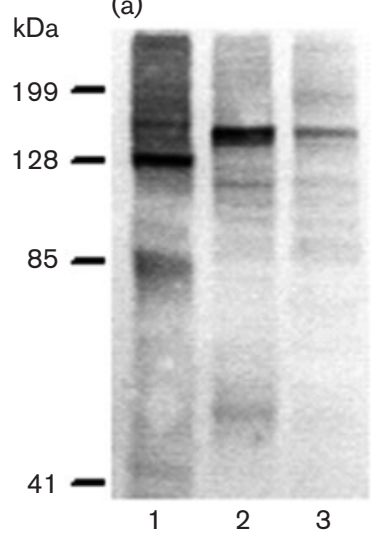

(b)

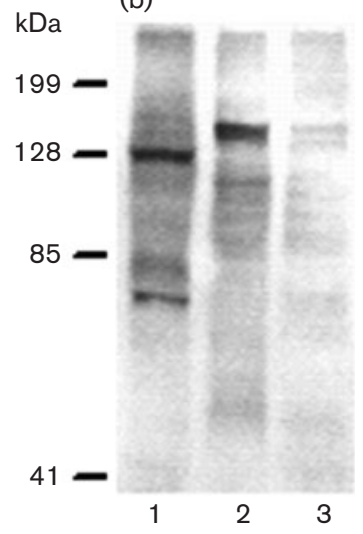

Fig. 5. Western blot analysis of FimH binding to lysates from human cell lines and chicken enterocytes. Binding of FimH adhesins from Salmonella Enteritidis (a) and Salmonella Typhimurium (b) to chicken enterocytes (lane 1), human colon cancer HT-29 cell line (lane 2) and human bladder cancer $\mathrm{Hu}$ $1703 \mathrm{He}$ cell line (lane 3). Cell lysates, equivalent to $100 \mu \mathrm{g}$ protein, were separated by SDS-PAGE under reducing conditions in a $7.5 \%$ gel and electrophoretically transferred onto nitrocellulose. The migration positions of protein standards (in $\mathrm{kDa}$ ) are indicated on the left. 
binding profiles were specific to the tested cell line. This was especially evident when human and chicken cells were compared. In lysates from human cell lines, the major component stained with FimH adhesins was represented by a band migrating at about $160 \mathrm{kDa}$, while in chicken erythrocytes it migrated at $126 \mathrm{kDa}$.

\section{SPR study}

The binding of Salmonella Enteritidis and Salmonella Typhimurium FimH adhesins to RNase B, HRP and mannan-BSA was analysed by SPR. Representative sensograms for the interaction of Salmonella Enteritidis FimH with immobilized glycoproteins are shown in Fig. 6(a-c). The sensograms were obtained by subtracting the curves recorded when the adhesin was passed over the blank surface from the response curves recorded for the FimH-glycoprotein interactions. The binding study was performed in the presence of $0.2 \mathrm{M} \mathrm{GuHCl}$ to decrease the non-specific binding of adhesin. Kinetic parameters of binding were obtained using a 1:1 Langmuir model allowing for separate calculation of the association $\left(k_{\mathrm{a}}\right)$ and dissociation $\left(k_{\mathrm{d}}\right)$ rate constants. The following values of the dissociation rate constants $\left(k_{\mathrm{d}}\right)$ were obtained for Salmonella Enteritidis: RNase B, $5 \cdot 1-5 \cdot 7 \times 10^{-3} \mathrm{~s}^{-1}$; HRP, 5.6-8.4 $\times 10^{-2} \mathrm{~s}^{-1}$; mannanBSA, $4 \cdot 1-6 \cdot 5 \times 10^{-2} \mathrm{~s}^{-1}$. Similarly, the association rate constants were: RNase $\mathrm{B}, 2 \cdot 1-2 \cdot 7 \times 10^{2} \mathrm{M}^{-1} \mathrm{~s}^{-1}$; HRP,
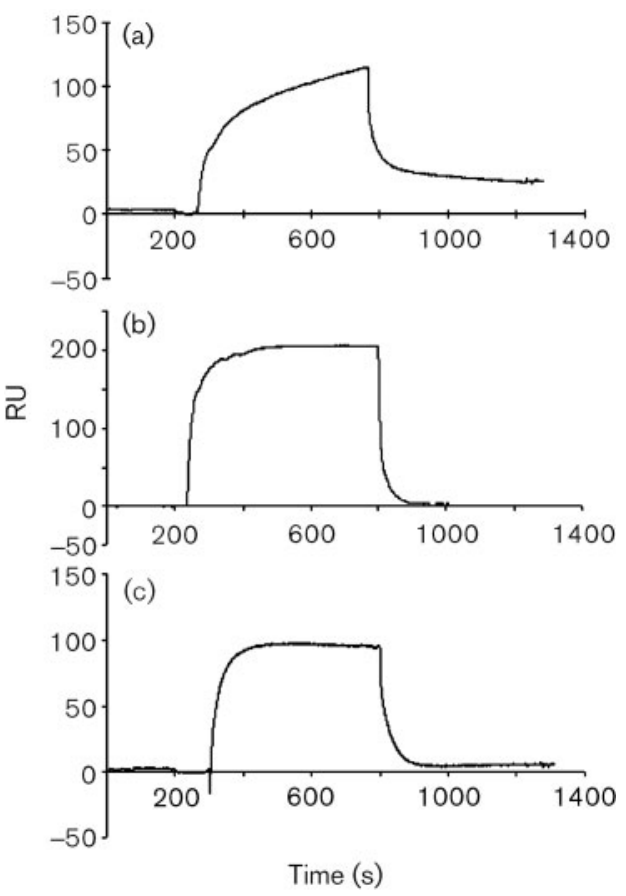

Fig. 6. Interaction of Salmonella Enteritidis FimH adhesin with immobilized RNase B (a), HRP (b) and mannan-BSA (c) analysed with the SPR biosensor. Salmonella Enteritidis FimH $\left(0.4 \mu \mathrm{g} \mathrm{ml}^{-1}\right)$ in TBS buffer containing $0.2 \mathrm{M} \mathrm{GuHCl}$ was passed over surface-bound glycoproteins. The response of the reference cell has been subtracted.
$0 \cdot 7-1 \cdot 0 \times 10^{2} \mathrm{M}^{-1} \mathrm{~s}^{-1} ;$ mannan-BSA, $1 \cdot 2-2 \cdot 8 \times 10^{1} \mathrm{M}^{-1}$ $\mathrm{s}^{-1}$. The $k_{\mathrm{d}} / k_{\mathrm{a}}$ ratio provided the following estimates of $K_{\mathrm{d}}$ : RNase B, $2 \cdot 0-2.5 \times 10^{-5} \mathrm{M}$; HRP, $1 \cdot 2-1.4 \times 10^{-3} \mathrm{M}$; mannan-BSA, $1.6-3.5 \times 10^{-3} \mathrm{M}$. In the case of serovar Typhimurium FimH adhesin, the sensograms obtained did not allow us to calculate the binding parameters for each of the three immobilized glycoproteins. The main reason for this was the high value recorded when the adhesin was passed over the blank surface, even in the presence of $0 \cdot 2 \mathrm{M} \mathrm{GuHCl}$.

\section{Mannose-sensitive adherence of Salmonella Enteritidis and Salmonella Typhimurium to human colon HT-29 and bladder Hu 1703He cancer cells}

In addition to the binding assay performed with isolated recombinant FimH adhesins, their binding specificity was verified by the adherence of intact Salmonella Enteritidis and Salmonella Typhimurium cells to human HT-29 and Hu $1703 \mathrm{He}$ monolayers. Both Salmonella strains exhibited strong binding to eukaryotic cells after five passages in LB broth at $37^{\circ} \mathrm{C}$ (Fig. $\left.7 \mathrm{a}, \mathrm{b}\right)$. This binding was abolished in the presence of $0 \cdot 2 \mathrm{M}$ mannose.

\section{Detection of FimH proteins on the surface of different Salmonella serovars by flow cytometry}

The expression of FimH adhesins on the surface of Salmonella Enteritidis and Salmonella Typhimurium was quantified

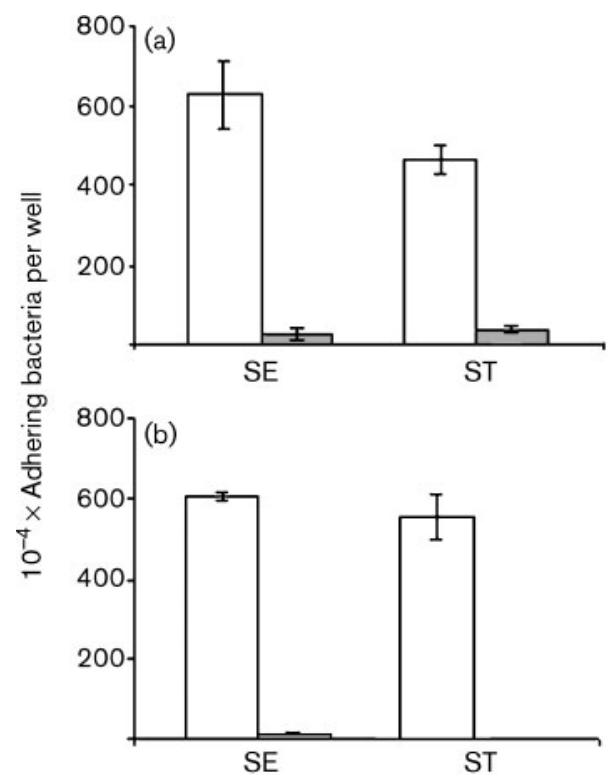

Fig. 7. Adherence of Salmonella Enteritidis (SE) and Salmonella Typhimurium (ST) to human colon cancer HT-29 (a) and bladder cancer $\mathrm{Hu} 1703 \mathrm{He}$ (b) cells in the absence (white bars) and the presence (grey bars) of $0.2 \mathrm{M} \mathrm{D}$-mannose. Bacteria were grown statically at $37^{\circ} \mathrm{C}$ in LB broth. After five passages, bacteria $\left(10^{8}\right)$ were incubated overnight with cell monolayers growing in 24-well plates. Data are means \pm SD from triplicate assays. 
by flow cytometry using rabbit anti-FimH antibodies and FITC-conjugated goat anti-rabbit IgG. For the detection of bacterial cells, DNA staining with propidium iodide was performed. It was found that in the case of both the analysed Salmonella serovars, the majority ( $>90 \%$ ) of bacteria were stained with anti-FimH antibodies (Fig. 8a, b). These data were obtained after five passages of bacteria in LB broth at $37^{\circ} \mathrm{C}$. In contrast, as expected, Salmonella Enteritidis harvested from SB agar did not bind anti-FimH antibodies (Fig. 8c), confirming the specificity of the anti-FimH antibodies used.

\section{DISCUSSION}

In previous work we cloned the fimH gene of Salmonella Enteritidis and Salmonella Typhimurium and found that the FimH proteins of these serovars differed only at four amino acid positions (L126R, Y131S, K137M, I317N) (Kisiela et al., 2005a, b). It should be noted that the FimH sequence of our wild-type Salmonella Typhimurium strain was the same as that of the Salmonella Typhimurium SL1344 strain described as a low-adhesive variant of this protein (Boddicker et al., 2002). In the present study, the binding specificities of the FimH proteins from Salmonella Enteritidis and Salmonella Typhimurium were analysed using three glycoproteins carrying different oligomannosidic structures: RNase B, HRP and mannan-BSA glycoconjugate. Both recombinant adhesins bound well and to the same extent to all three ligands carrying high-mannose oligosaccharides, as shown by Western blotting and ELISA. The lack of differences between the binding properties of the FimH adhesins from Salmonella Enteritidis and Salmonella Typhimurium can be explained by the presence of the same amino acid residues at specific positions, which, according to Boddicker et al. (2002), are very important for the adhesion of Salmonella Typhimurium to HEp-2 cells. These authors showed that FimH adhesins expressed by Salmonella Typhimurium strains with different adhesive properties differ by just two amino acids. The low-adhesive variant of FimH adhesin has a glycine residue at position 61 and phenylalanine at position 118, and the high-adhesive variant of this protein has alanine at position 61 and threonine at position 118. The fact that the FimH proteins of the Salmonella Enteritidis and Salmonella Typhimurium strains have the same amino acid residue at these positions as the low-adhesive variant suggests that the FimH proteins of both our Salmonella strains represent the low-adhesive variant of FimH as well. In addition to these two amino acid residues, our previous and present study with mutated forms of FimH adhesins from various Salmonella serovars showed that the binding to high-mannose oligosaccharides is critically dependent on the threonine residue at position 78. The replacement of isoleucine with threonine (I78T) in the FimH molecule by site-directed mutagenesis caused the inactive FimH proteins of Salmonella Gallinarum and Salmonella Pullorum to bind well to glycoproteins carrying high-mannose oligosaccharides (Kisiela et al., 2005b) and, conversely, the change of threonine to isoleucine (T78I) in active FimH molecules of Salmonella Enteritidis and Salmonella Typhimurium caused complete loss of their binding properties.

In addition to the static binding assays, the binding specificity of Salmonella FimH adhesins was further studied by direct kinetic analysis using SPR. With this method we found that Salmonella Enteritidis FimH bound with the highest $K_{\mathrm{d}}$ value to high-mannose $N$-glycans carried by RNase B. This glycoprotein carries a single N-glycan, although it is found in five different glycoforms (Fu et al., 1994) that are all high-mannose $N$-glycans built with different numbers of mannose residues $\left(\mathrm{Man}_{5-9}\right)$. A characteristic feature of these oligosaccharides is the presence of mannosyl residues attached by $\alpha-(1 \rightarrow 2)$ linkages beyond the branch point (Fu et al., 1994). However, the major structure is the pentasaccharide core with two additional mannosyl residues (structure 3, Table 1). Our results are in full agreement with the data obtained by Firon et al. $(1983,1984)$, who showed
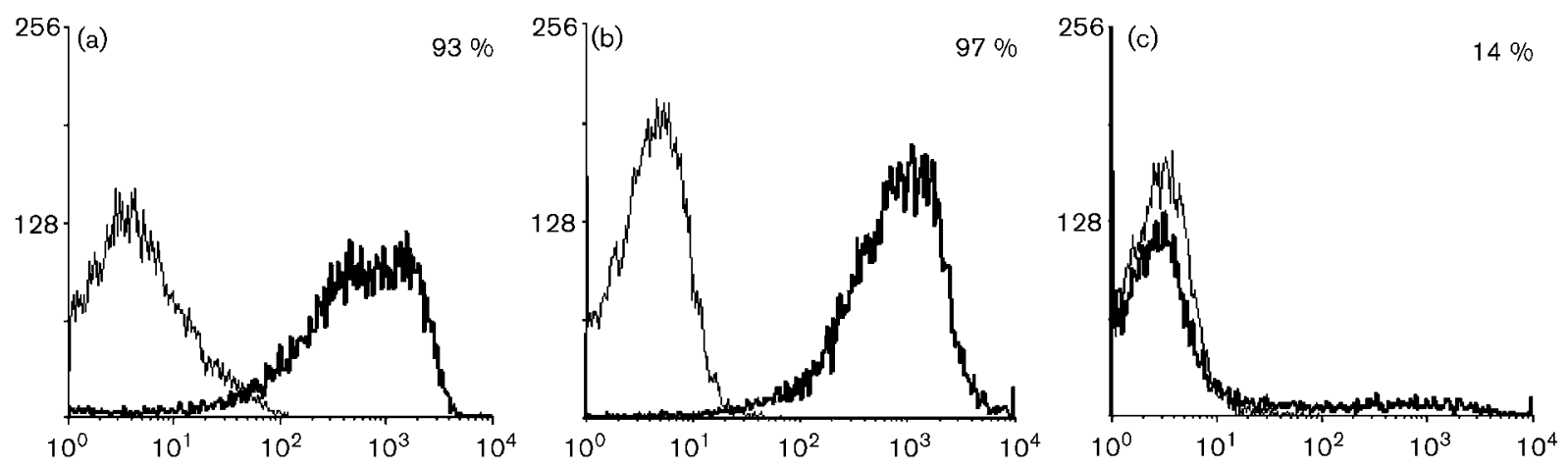

Fig. 8. Flow cytometric analysis of FimH expression on Salmonella Enteritidis (a), Salmonella Typhimurium (b) grown statically at $37^{\circ} \mathrm{C}$ in LB broth and Salmonella Enteritidis (c) grown on SB agar. Thick lines show the binding of rabbit polyclonal antiFimH antibodies. Thin lines show the non-specific binding of the secondary goat antibody directed against rabbit immunoglobulins. The percentage of cells with fluorescence intensities that lie within the gated area is shown in the top right corner of each histogram. 
that similar structures are the best ligands for the type 1 fimbriae of Salmonella Typhimurium (Table 1, structures 1 and 2). About 100 times lower $K_{\mathrm{d}}$ values were obtained for the interactions with HRP and mannan-BSA. The main structure of the $\mathrm{N}$-glycan carried by HRP is shown in Table 1 (oligosaccharide 4). It represents the core structure of an $\mathrm{N}$-linked carbohydrate chain with an additional xylose residue $\alpha(1 \rightarrow 2)$-linked to the subterminal mannose (Kurosaka et al., 1991). More recently, Takahashi et al. (1998) showed a considerable degree of heterogeneity in the structures of HRP $N$-glycans, including a small number of structures devoid of xylose. Mannan-BSA, a synthetic neoglycoprotein, contains derivatives of Saccharomyces cerevisiae mannan (structure 5$)$, which has an $\alpha(1 \rightarrow 6)$-linked D-mannose backbone with side chains containing $\alpha(1 \rightarrow 2)$ and $\alpha(1 \rightarrow 3)$-linked D-mannose units (Raschke \& Ballou, 1972). Such side chains correspond to linear di- and oligomannosidic structures shown by Firon et al. $(1983,1984)$ to be poor inhibitors of yeast agglutination. This finding stresses the importance of the branched, unsubstituted mannosidic units in the binding by Salmonella FimH adhesin. Unfortunately, in contrast to the serovar Enteritidis, we were unable to calculate the kinetic parameters for serovar Typhimurium FimH by SPR because of the much higher non-specific binding of this protein, probably because of its higher hydrophobicity, even in the presence of $\mathrm{GuHCl}$.

Despite intensive study of type 1 fimbriae in Salmonella spp., there is surprisingly little information on the binding specificity of their FimH adhesins to different types of eukaryotic cells. Thankavel et al. (1999) recently showed that Salmonella Typhimurium as well as its isolated type 1 fimbriae bind to mouse enterocytes, but not to mouse uroepithelial cells. According to these authors, FimH adhesins, as an integral part of type 1 fimbriae but not as free proteins, are responsible for such differences. In contrast, in our studies, Salmonella Typhimurium and Salmonella Enteritidis cells as

Table 1. Structures of mannosylated oligosaccharides bound by FimH adhesins from Salmonella Enteritidis and Salmonella Typhimurium

Structures of mannosylated oligosaccharides

1

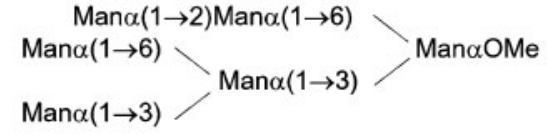

2

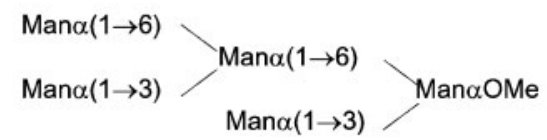

3

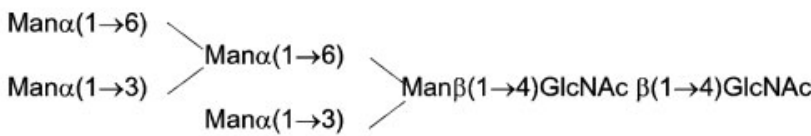

4

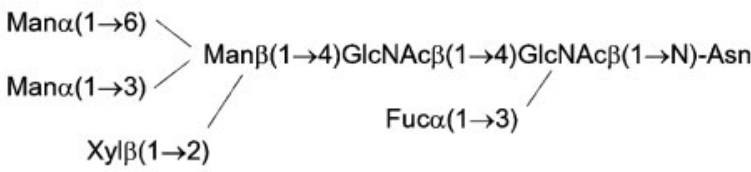

5

\section{Reference}

Firon et al. (1984)

Firon et al. (1984)

Fu et al. (1994)

Kurosaka et al. (1991)

Raschke \& Ballou (1972) 
well as isolated FimH adhesins of these serovars bound almost equally well to human colon carcinoma or bladder cancer cells. To exclude the possibility that the observed binding is influenced by the differences in the levels of expression of FimH proteins on the surfaces of these two different serovars, flow cytometry analysis with specific antiFimH antibodies was performed; this showed that these two Salmonella serovars express the same level of FimH protein on their surface. What are the reasons for such discrepancies between our findings and those of Thankavel et al. (1999)? Comparison of the amino acid sequence of FimH protein from the Salmonella Typhimurium strain that they used revealed that it is identical to Salmonella Typhimurium strain LB5010 described by Boddicker et al. (2002) as the high-adhesive allelic variant of this protein. In contrast, the FimH adhesins from Salmonella Typhimurium and Salmonella Enteritidis strains used by us correspond to the lowadhesive allelic variant described by these latter authors. Therefore it is possible that high-adhesive variants of FimH proteins are able to discriminate between different eukaryotic cells in contrast to low-adhesive ones. Interestingly, our analysis of fimH genes from 13 avian and 8 human Salmonella Enteritidis isolates revealed that all the strains analysed represent low-adhesive variants (Kisiela et al., 2005a). At this point it is difficult to discuss the biological significance of our findings. Further studies with mutated forms of FimH proteins representing low- and high-adhesive variants should help in addressing this question.

The use of soluble recombinant adhesins allowed us to perform a preliminary characterization of their potential receptors present on eukaryotic cells. Using Western blotting, we have shown that both the adhesins investigated here bound to numerous glycoproteins expressed by all the analysed cell lines. However, in the human cell lines analysed there was one major stained component represented by a band migrating at $160 \mathrm{kDa}$, and in the case of chicken enterocytes one major component at $128 \mathrm{kDa}$. The binding of FimH was completely inhibited by D-mannose, which is a good indication of the specificity of these interactions. The presence of multiple bands stained with adhesins is not surprising, as many eukaryotic cell glycoproteins carry high-mannose-type chains. In addition, because we used cell lysates, the samples may contain many unprocessed $\mathrm{N}$-glycans with high-mannose structures.

In summary, in the present study the functional characterization of the FimH adhesins of Salmonella Enteritidis and Salmonella Typhimurium revealed close similarities between these two proteins. Both adhesins, representing low-adhesive allelic variants of FimH protein (Boddicker et al., 2002), bound to different high-mannose structures. However, SPR analysis stressed the importance of the branched, unsubstituted mannosidic units in the binding, as was shown for Salmonella Enteritidis. In addition, site-directed mutagenesis of these two adhesins confirmed the importance of a single T78I mutation responsible for the loss of sugar-binding properties by these proteins. Preliminary characterization of natural receptors present in human and chicken cells showed that, despite the fact that FimH proteins bind to numerous glycoproteins, some of them were stained preferentially, suggesting the presence of specific ligands recognized by these adhesins. Further studies will be necessary to better characterize these glycoproteins.

\section{ACKNOWLEDGEMENTS}

This work was supported by Grant no. 3PO6K 00322 of the State Committee for Scientific Research (KBN), Warsaw, Poland.

\section{REFERENCES}

Abraham, S. N. (1994). Bacterial adhesins. In Adhesion Molecules, pp. 253-276. Edited by C. D. Wegner. London: Academic Press.

Abraham, S. N., Sun, D., Dale, J. B. \& Beachey, E. H. (1988). Conservation of the D-mannose-adhesion protein among type 1 fimbriated members of the family Enterobacteriaceae. Nature 336, 682-684.

Allen-Vercoe, E. \& Woodward, M. J. (1999). The role of flagella, but not fimbriae, in the adherence of Salmonella enterica serotype Enteritidis to chick gut explants. J Med Microbiol 48, 771-780.

Allen-Vercoe, E., Sayers, A. R. \& Woodward, M. J. (1999). Virulence of Salmonella enterica serotype Enteritidis aflagellate and afimbriate mutants in a day-old chick model. Epidemiol Infect 122, 395-402.

Barrow, P. A. (1998). Virulence of Salmonella enterica serovar Enteritidis. In Salmonella Enterica Serovar Enteritidis in Humans and Animals: Epidemiology, Pathogenesis and Control, pp. 173-182. Edited by A. M. Saeed, R. K. Gast, M. Potter \& P. G. Wall. Ames: Iowa State University Press.

Boddicker, J. D., Ledeboer, N. A., Jagnow, J., Jones, B. D. \& Clegg, S. (2002). Differential binding to and biofilm formation on, HEp-2 cells by Salmonella enterica serovar Typhimurium is dependent upon allelic variation in the fimH gene of the fim gene cluster. Mol Microbiol 45, 1255-1265.

Boratynski, J. \& Roy, R. (1998). High temperature conjugation of proteins with carbohydrates. Glycoconj J 15, 131-138.

Christensen, B., Kieler, J., Vilien, M., Don, P., Wang, C. Y. \& Wolf, H. (1984). A classification of human urothelial cells propagated in vitro. Anticancer Res 4, 319-338.

Clegg, S. \& Gerlach, G. F. (1987). Enterobacterial fimbriae. J Bacteriol 169, 934-938.

Clouthier, S. C., Müller, K.-H., Doran, J. L., Collinson, S. K. \& Kay, W. W. (1993). Characterization of three fimbrial genes, sefABC, of Salmonella enteritidis. J Bacteriol 175, 2523-2533.

Collinson, S. K., Clouthier, S. C., Doran, J. L., Banser, P. A. \& Kay, W. W. (1996). Salmonella enteritidis agfBAC operon encoding thin, aggregative fimbriae. J Bacteriol 178, 662-667.

De Buck, J., Van Immerseel, F., Meulemans, G., Haesebrouck, F. \& Ducatelle, R. (2003). Adhesion of Salmonella enterica serotype Enteritidis isolates to chicken isthmal glandular secretions. Vet Microbiol 93, 223-233.

Dibb-Fuller, M. P. \& Woodward, M. J. (2000). Contribution of fimbriae and flagella of Salmonella enteritidis to colonization and invasion of chicks. Avian Pathol 29, 295-304.

Dibb-Fuller, M. P., Allen-Vercoe, E., Thorns, C. J. \& Woodward, M. J. (1999). Fimbriae- and flagella-mediated association with and invasion of cultured epithelial cells by Salmonella enteritidis. Microbiology 145, 1023-1031. 
Duguid, J. P., Anderson, E. S. \& Campbell, I. (1966). Fimbriae and adhesive properties in Salmonellae. J Pathol Bacteriol 92, 107-138.

Duk, M., Lisowska, E., Wu, J. H. \& Wu, A. M. (1994). The biotin/ avidin-mediated microtiter plate lectin assay with the use of chemically modified glycoprotein ligand. Anal Biochem 221, 266-272.

Edwards, R. A., Olsen, G. J. \& Maloy, S. R. (2002). Comparative genomics of closely related salmonellae. Trends Microbiol 10, 94-99.

Ewen, S. W., Naughton, P. J., Grant, G., Sojka, M., Allen-Vercoe, E., Bardocz, S., Thorns, C. J. \& Pusztai, A. (1997). Salmonella enterica var Typhimurium and Salmonella enterica var Enteritidis express type 1 fimbriae in the rat in vivo. FEMS Immunol Med Microbiol 18, 185-192.

Firon, N., Ofek, I. \& Sharon, N. (1983). Carbohydrate specificity of the surface lectins of Escherichia coli, Klebsiella pneumoniae and Salmonella typhimurium. Carbohydr Res 120, 235-249.

Firon, N., Ofek, I. \& Sharon, N. (1984). Carbohydrate-binding sites of the mannose-specific fimbrial lectins of enterobacteria. Infect Immun 43, 1088-1090.

Fu, D., Chen, L. \& O'Neill, R. A. (1994). A detailed structural characterization of ribonuclease B oligosaccharides by ${ }^{1} \mathrm{H}$ NMR spectroscopy and mass spectrometry. Carbohydr Res 261, 173-186.

Hancox, L. S., Kuang-Sheng, Y. \& Clegg, S. (1998). Construction and characterization of type 1 non-fimbriate and non-adhesive mutants of Salmonella typhimurium. FEMS Immunol Med Microbiol 19, 289-296.

Humphries, A. D., Raffatellu, M., Winter, S. \& 10 other authors (2003). The use of flow cytometry to detect expression of subunits encoded by 11 Salmonella enterica serotype Typhimurium fimbrial operons. Mol Microbiol 48, 1357-1376.

Kimmich, G. A. (1970). Preparation and properties of mucosal epithelial cells isolated from small intestine of the chicken. Biochemistry 9, 3659-3668.

Kisiela, D., Kiczak, L., Kuzminska, M., Kuczkowski, M., Franiczek, R. \& Ugorski, M. (2005a). Analysis of the fimH gene coding type 1 fimbriae adhesin of Salmonella enterica serovar Enteritidis. Med Wet 61, 1259-1262.

Kisiela, D., Sapeta, A. M., Kuczkowski, M., Stefaniak, T., Wieliczko, A. \& Ugorski, M. (2005b). Characterization of FimH adhesins expressed by Salmonella enterica serovar Gallinarum biovars Gallinarum and Pullorum: reconstitution of mannose-binding properties by single amino acid substitution. Infect Immun 73, 6187-6190.

Krogfelt, K. A., Bergmans, H. \& Klemm, P. (1990). Direct evidence that the FimH protein is the adhesin of Escherichia coli type 1 fimbriae. Infect Immun 58, 1995-1999.

Kurosaka, A., Yano, A., Nobuyuki, I., Kuroda, Y., Nakagawa, T. \& Kawasaki, T. (1991). The structure of a neural specific carbohydrate epitope of horseradish peroxidase recognized by anti-horseradish peroxidase antiserum. J Biol Chem 266, 4168-4172.

Laemmli, U. K. (1970). Cleavage of structural proteins during the assembly of the head of the bacteriophage T4. Nature 227, 680-685.

Müller, K.-H., Collinson, K., Trust, T. J. \& Kay, W. W. (1991). Type 1 fimbriae of Salmonella enteritidis. J Bacteriol 173, 4765-4772.

Old, D. C. (1972). Inhibition of interaction between fimbrial haemagglutinins and erythrocytes by D-mannose and other carbohydrates. J Gen Microbiol 71, 149-157.

Naughton, P. J., Grant, G., Bardocz, S., Allen-Vercoe, E., Woodward, M. J. \& Pusztai, A. (2001). Expression of type 1 fimbriae (SEF 21) of Salmonella enterica serotype enteritidis in the early colonisation of the rat intestine. J Med Microbiol 50, 191-197.

Porwolik, S. \& McClelland, M. (2003). Lateral gene transfer in Salmonella. Microb Infect 5, 977-989.

Rajashekara, G., Munir, S., Alexeyev, M. F., Halvorson, D. A., Wells, C. L. \& Nagaraja, K. V. (2000). Pathogenic role of SEF14, SEF17, and SEF21 fimbriae in Salmonella enterica serovar Enteritidis infection of chickens. Appl Environ Microbiol 66, 1759-1763.

Raschke, W. C. \& Ballou, C. E. (1972). Characterization of a yeast mannan containing $N$-acetyl-D-glucosamine as an immunochemical determinant. Biochemistry 11, 3807-3816.

Sohel, I., Puente, J. L., Murray, W. J., Vuopio-Varkila, J. \& Schoolnik, G. K. (1993). Cloning and characterization of the bundle-forming pilin gene of enteropathogenic Escherichia coli and its distribution in Salmonella serotypes. Mol Microbiol 7, 563-575.

Sokurenko, E. V., Courtney, H. S., Ohman, D. E., Klemm, P. \& Hasty, D. L. (1994). FimH family of type 1 fimbrial adhesins: functional heterogeneity due to minor sequence variations among fim $\mathrm{H}$ genes. J Bacteriol 176, 748-755.

Sokurenko, E. V., Courtney, H. S., Maslow, J., Siitonen, A. \& Hasty, D. L. (1995). Quantitative differences in adhesiveness of type 1 fimbriated Escherichia coli due to structural differences in fim $\mathrm{H}$ genes. J Bacteriol 177, 3680-3686.

Takahashi, N., Lee, B. K., Nakagawa, H., Tsukamoto, Y., Masuda, K \& Lee, Y. C. (1998). New $\mathrm{N}$-glycans in horseradish peroxidase. Anal Biochem 255, 183-187.

Thankavel, K., Shah, A. H., Cohen, M. S., Ikeda, T., Lorenz, R. G., Curtiss, R. \& Abraham, S. N. (1999). Molecular basis for the enterocyte tropism exhibited by Salmonella typhimurium type 1 fimbriae. J Biol Chem 274, 55797-55809.

Thorns, C. J. (1995). Salmonella fimbriae: novel antigens in the detection and control of Salmonella infections. Br Vet J 151, 643-658.

Woodward, M. J., Allen-Vercoe, E. \& Redstone, J. S. (1996). Distribution, gene sequence and expression in vivo of the plasmid encoded fimbrial antigen of Salmonella serotype Enteritidis. Epidemiol Infect 117, 17-28. 